Volume 8, No.5, September - October 2019

International Journal of Advanced Trends in Computer Science and Engineering

Available Online at http://www.warse.org/IJATCSE/static/pdf/file/ijatcse76852019.pdf https://doi.org/10.30534/ijatcse/2019/76852019

\title{
Genetic Algorithm based Direct Torque Control of VSI fed Induction Motor Drive using MATLAB Simulation
}

\author{
Bibhu Prasad Ganthia ${ }^{1}$, Satish Ranjan Sahu ${ }^{2}$, Sarthak Biswal ${ }^{3}$, Amruta Abhisekh ${ }^{4}$, Dr. Subrat Kumar Barik \\ ${ }^{1} \mathrm{PhD}$ Research Scholar, School of Electrical Engineering, KIIT University, India, jb.bibhu@ gmail.com \\ ${ }^{2}$ M.Tech, PED, Electrical Engineering, IGIT, Sarang, Dhenkanal, Odisha,India, satishranjan543@ gmail.com \\ ${ }^{3}$ M.Tech, PSE, Electrical Engineering, IGIT, Sarang, Dhenkanal, Odisha,India, biswalsarthak02@ gmail.com \\ ${ }^{4}$ M.Tech, PSE, Electrical Engineering, IGIT, Sarang, Dhenkanal, Odisha,India, amrutaabhishek45@gmail.com \\ ${ }^{5}$ Associate Professor, School of Electrical Engineering, KIIT University, India, skbarikfel@kiit.ac.in
}

\begin{abstract}
Induction motors are the starting point to design an electrical drive system which is widely used in many industrial applications. In modern control theory, different mathematical models describe induction motor according to the employed control methods. Vector control strategy can be applied to this electrical motor type in symmetrical three phase version or in unsymmetrical two phase version. The operation of the induction motor can be analyzed similar to a DC motor through this control method. With the Joint progress of the power electronics and numerical electronics it is possible today to deal with the axis control with variable speed in low power applications. With these technological projections, various command approaches have been developed by the scientific community to master in real time, the flux and the torque of the electrical machines, the direct torque control (DTC) scheme being one of the most recent steps in this direction. This scheme provides excellent properties of regulation without rotational speed feedback. In this control scheme the electromagnetic torque and stator flux magnitude are estimated with only stator voltages and currents and this estimation does not depend on motor parameters except for the stator resistance. [1][2] In this paper conventional DTC scheme has been described using MATLAB coding for switching control of VSI where the Induction motor has been simulated in stationary $\mathrm{d}$-q reference frame. Conventional DTC scheme has been studied to acquire brief theoretical knowledge about this control strategy. Literature review has also been done to study the recent improvements in DTC scheme which somehow is able to overcome the drawbacks of conventional one. On this regard Genetic Algorithms are used for tuning of PI controller to decide the optimized value of $\mathrm{Kp}$ and $\mathrm{Ki}$ which reduces the torque, flux and current ripple. [3]
\end{abstract}

Key words: Induction motor, mathematical d-q modeling, VSI, vector control, DTC, PI controller, Genetic Algorithm \& optimization technique.

\section{INTRODUCTION}

Over the past decades DC machines were used extensively for variable speed applications due to the decoupled control of torque and flux that can be achieved by armature and field current control respectively. DC drives are advantageous in many aspects as in delivering high starting torque, ease of control and nonlinear performance. But due to the major drawbacks of DC machine such as presence of mechanical commutator and brush assembly, DC machine drives have become obsolete today in industrial applications. The robustness, low cost, the better performance and the ease of maintenance make the asynchronous motor advantageous in many industrial applications or general applications. Squirrel cage induction motors (SCIM) are more widely used than all the rest of the electric motors as they have all the advantages of AC motors and are cheaper in cost as compared to Slip Ring Induction motors; require less maintenance and rugged construction [4].

\subsection{Induction Motor Drives}

The IM is the most widely used AC motor as it offers several advantages compared to other motors. There are two types of three-phase IMs.

- $\quad$ Squirrel-cage IM

- Wound -rotor IM

From the electrical point of view, both the machines are identical except the former has rotor winding terminals permanently shorted inside the machine. In case of wound-rotor machine, the terminals of the rotor three-phase winding are externally available to the user. The project deals with speed control of Squirrel-cage IM only. The block diagram of a typical modern variable speed IM drive system is shown in Figure 1. The IM is connected directly or indirectly (through gears) to the load. The power converter controls the power flow from an ac supply to the motor by appropriate control of power semiconductor switches (part of power converter) [5]. 


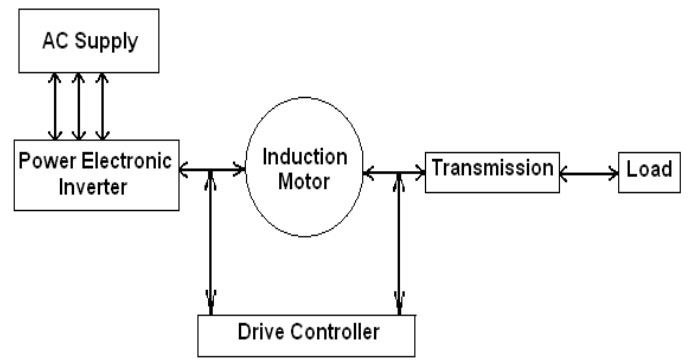

Figure 1: Modern variable speed IM drive system [1]

IM drives with cage type machines have been the workhorses in industry for variable-speed applications in a wide power range that covers from fractional horse power to multi-mega watts. These applications include pumps and fans, paper and textile mills, subway and locomotive propulsions, electric and hybrid vehicles, machine tools and robotics, home appliances, heat pumps and air conditioners, rolling mills, wind generation systems, etc. The IM is preferable as they have such features, as being maintenance free in operation, are rugged and reliable machines over their counterparts [4]. They can be designed as totally enclosed motors to operate in dirty and explosive environment. The control and estimation of ac drives such as the IM in general are considerably more complex than those of dc drives, and this complexity increases substantially if high performances are demanded. The main reasons for this complexity are the need of variable-frequency, harmonically optimum converter power supplies, the complex dynamics of ac machines, machine parameter variations, and the difficulties of processing feedback signals in the presence of harmonics [6].

\subsection{Dynamic Model of Induction Motor}

Dynamic modeling and simulation of induction motor drives is of great importance to both industry and academia due to the prevalence of these types of drives in various industrial settings shown in figure 2. Dynamic simulations play an important role in the pre-testing of motor drive systems [20]. Pre-testing is conducted by engineers in industry as well as by researchers in academia. Pre-testing using dynamic simulations can help researchers determine the experimental setup that will be used for a given set of experimental tests. Simulink allows electrical engineers to model dynamical systems with ease using a block diagram approach that can be constructed fast and efficiently [7][35].

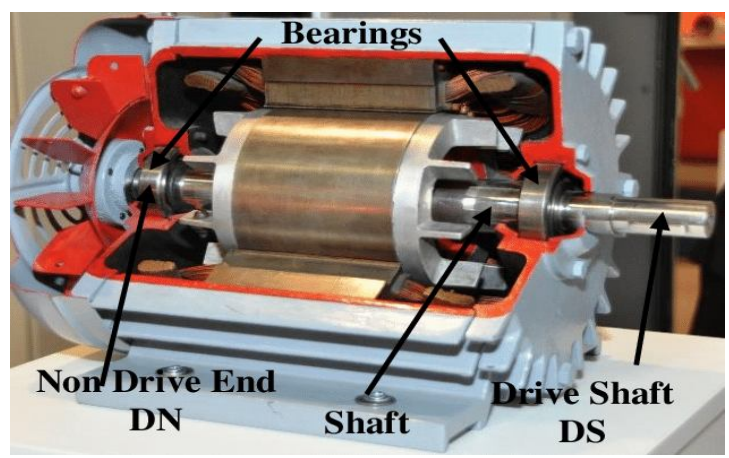

Figure 2: Hardware design of IM drive system [12]
However, most of them do not give details as to how the model equations and subsystems within the model are derived. The stator of induction motor consists of three phase balanced distributed windings with each phase separated from other two windings by 120 degrees in space. When current flows through these windings, three phase rotating magnetic field is produced. The dynamic behavior of the induction machine is taken into account in an adjustable speed drive system using a power electronics converter [9][10].

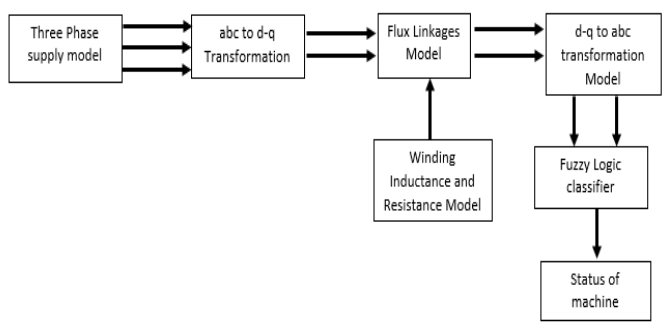

Figure 3: Block diagram of induction machine [5]

This machine constitutes an element within a feedback loop. Study of the dynamic performance of the machine is complex due to coupling effect of the stator and rotor windings; also the coupling coefficient varies with rotor position. So a set of differential equations with time varying coefficients describe the machine model [8][24]. These models are derived by using $d$ and $q$ variables in a stationary rotating reference frame shown in figure 3.

\subsection{Voltage Source Inverter}

In VSIs the input voltage is maintained constant and the amplitude of the output voltage is independent of the nature of the load. But the output current waveform as well as magnitude depends upon nature of load impedance. Three phase VSIs are more common for providing adjustable frequency power to industrial applications as compared to single phase inverters. The VSIs take dc supply from a battery or more usually from a $3-\phi$ bridge rectifier. A basic three phase VSI is a six step bridge inverter, consisting of minimum six power electronics switches (i.e. IGBTs, Thyristors) and six feedback diodes [12][25]. A step can be defined as the change in firing from one switch to the next switch in proper sequence. For a six step inverter each step is of $60^{\circ}$ interval for one cycle of $360^{\circ}$. That means the switches would be gated at regular intervals of $60^{\circ}$ in proper sequence to get a three phase ac output voltage at the output terminal of VSI. Figure 4 shows the power circuit diagram of three phase VSI using six IGBTs and six diodes connected anti parallel to the IGBTs. The capacitor connected in to the input terminals is to maintain the input dc voltage constant and this also suppresses the harmonics fed back to the dc source. Three phase load is star connected [11][28]. 


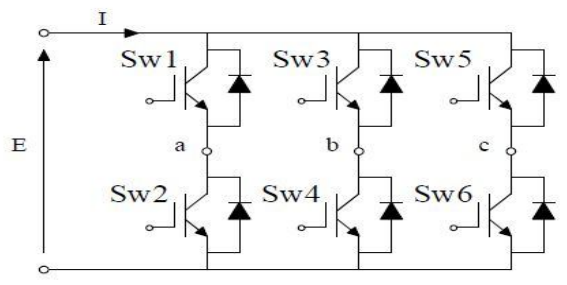

Figure 4: Line diagram of a three phase VSI [2]

\section{DIRECT TORQUE CONTROL OF INDUCTION MOTOR}

The Direct torque control (DTC) technique has been recognized as the simple and viable solution to achieve this requirements.DTC is one of the most excellent and efficient control strategies of induction motor. This technique is based on decoupled control of torque and stator flux and today it is one of the most actively researched control techniques where the aim is to control effectively the torque and flux. The DTC scheme does not require coordinate transformation as all the control procedures are carried out in stationary frame of reference. So this scheme does not suffer from parameter variations to the extent that other control techniques do. Also there is no feedback current control loop due to which the control actions do not suffer from the delays inherent in the current controllers, no pulse width modulator, no PI controllers, and no rotor speed or position sensor. So it is a sensorless control technique which operates the motor without requiring a shaft mounted mechanical sensor. Here on-line torque and flux estimators are used for closing the loop. Here the torque and stator flux are controlled directly by using hysteresis comparators [13]. Figure 5 shows the basic block diagram of conventional DTC scheme.

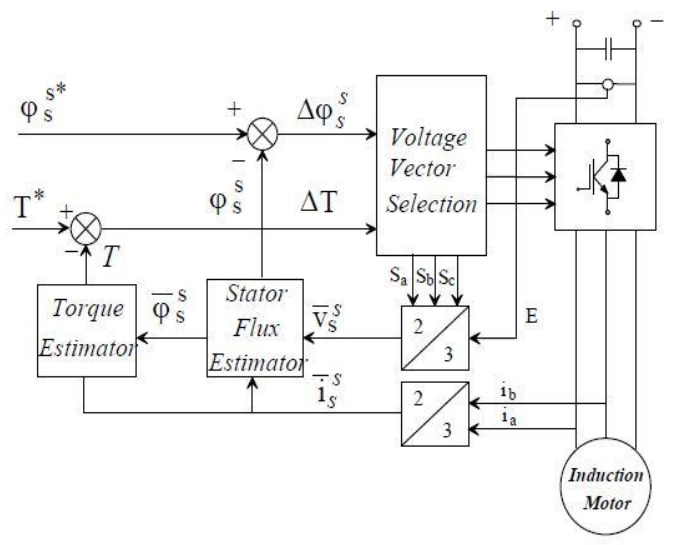

Figure 5: Basic block diagram of conventional DTC scheme [8]

\subsection{DTC Scheme}

The Direct Torque Control is based on the theory on the Field Oriented Control of Induction machine [11] and the theory of Direct Self Control [12]. A spatial vector presentation of motor quantities is used. Flux and Current vectors and inverter voltage can be represented in stator co-ordinates as six active voltage vectors and two zero-voltage vectors are available in two-level voltage source inverter shown in figure 6.

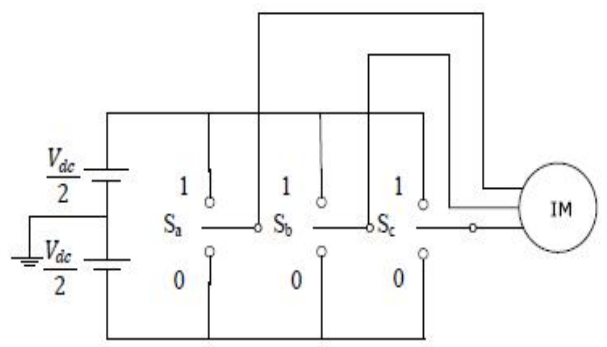

Figure 6: Simplified 3- $\phi$ VSI

The basic principle of DTC is to directly select stator voltage vectors according to the torque and flux errors which are the differences between the references of torque and stator flux linkage and their actual values. The governing equation for torque for this scheme is due to the interaction of stator and rotor fields. Torque and stator flux linkage are computed from measured motor terminal quantities i.e. stator voltages and current. An optimal voltage vector for the switching of VSI is selected among the six nonzero voltage vectors and two zero voltage vectors by the hysteresis control of stator flux and torque [14][34].

\subsection{DTC Technique using Hysteresis Torque and Flux Controller}

The control command for the system is speed. The Flux reference can be calculated based on the speed. Below the rated speed, rated flux is used as a reference (constant torque region). Above the rated speed; flux-weakening method generates the flux reference (constant power region). The reference flux is selected, proportional to the inverse of the reference speed. The reference torque can be calculated using the difference between reference speed and instantaneous speed (using a PI controller). Selection of such reference speed improves the dynamic response of the torque and flux control [11][12][13].

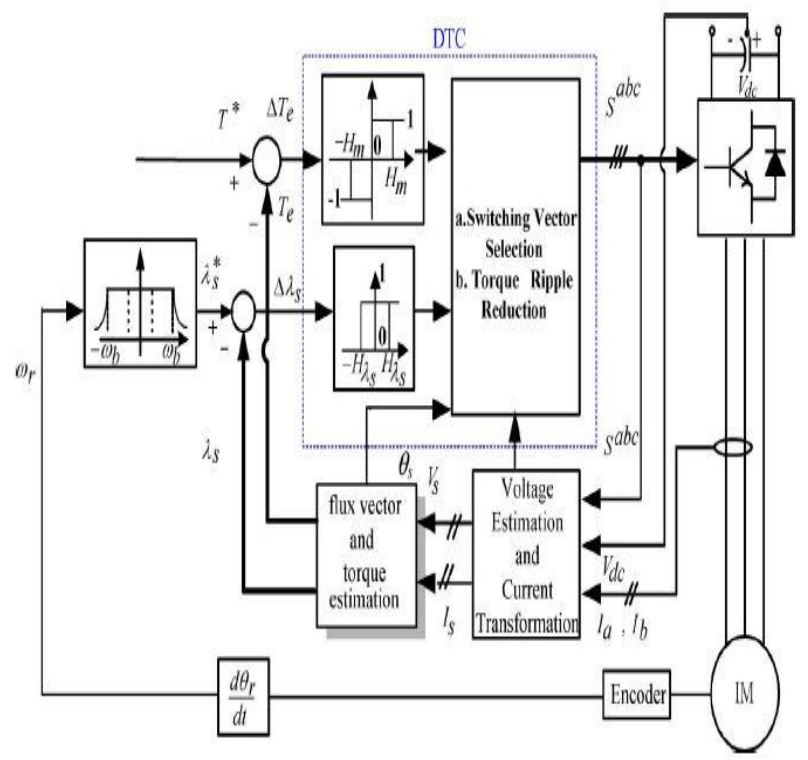

Figure 7: Block diagram of DTC scheme using hysteresis torque \& flux controller 
The block diagram of DTC scheme shown in above figure 7 and reference frame of stator and rotor axis shown in figure number 8 . The control command for the system is speed. The Flux reference can be calculated based on the speed. Below the rated speed, rated flux is used as a reference (constant torque region). Above the rated speed; flux-weakening method generates the flux reference (constant power region). The reference flux is selected, proportional to the inverse of the reference speed. The reference torque can be calculated using the difference between reference speed and instantaneous speed (using a PI controller). Selection of such reference speed improves the dynamic response of the torque and flux control [11][14].

The electromagnetic torque produced due to interaction of stator and rotor flux is given by the following equation:

$$
\mathrm{T}_{\mathrm{e}}=\frac{3}{2}\left(\frac{P}{2}\right) \frac{L_{m}}{L_{s}^{\prime} L_{r}} \overline{\Psi_{s}} * \overline{\Psi_{r}}=\frac{3}{2}\left(\frac{P}{2}\right) \frac{L_{m}}{L_{s}^{\prime} L_{r}} \Psi_{s} \Psi r \sin \gamma
$$

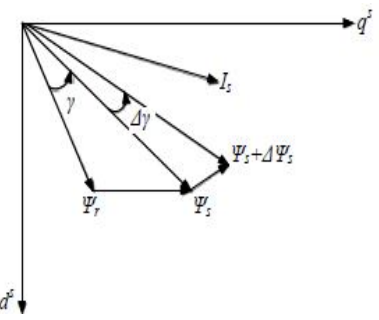

Figure 8: Stator flux, rotor flux and stator current vectors in $d^{s}-q^{s}$ reference plane.

From the above it is clear that torque varies directly as angle between stator flux and rotor flux i.e. $\gamma$. So in order to obtain high dynamic performance it is required to vary $\gamma$ quickly. Assuming the rotor is rotating in anticlockwise direction continuously and stator flux lies in sector $k$, the active forward voltage vectors $\left(V_{s, k+1}\right.$ and $\left.V_{s, k+2}\right)$ are applied to increase $\gamma$ so as the torque $T_{e}$. The radial voltage vectors $\left(V_{s, k}\right.$ and $\left.V_{s, k+3}\right)$ are used to decrease $\gamma$ and $T_{e}$. By applying the reverse active voltage vectors $\left(V_{s, k-1}\right.$ and $\left.V_{s, k-2}\right)$ torque can be decreased rapidly. The two zero voltage vectors $\left(V_{s, 0}\right.$ and $\left.V_{s, 7}\right)$ are applied to maintain the flux constant ideally and to decrease the torque slightly [12][15].

\subsubsection{Switching Selection}

A high performance torque control can be established due to the decoupled control of stator flux and torque in DTC. Figure 9 shows an example of stator flux located in sector-1 $\langle$ S(1) $\rangle$ with the corresponding optimum switching voltage vectors for anti-clockwise and clockwise rotation of the shaft [6][17].

Optimum switching vector selection table given by Table 1 shows the optimum selection of the switching vectors in all sectors of the stator flux plane. This table is based on the value of stator flux error status, torque error status and orientation of stator flux for counter-clockwise rotation of the shaft [8].
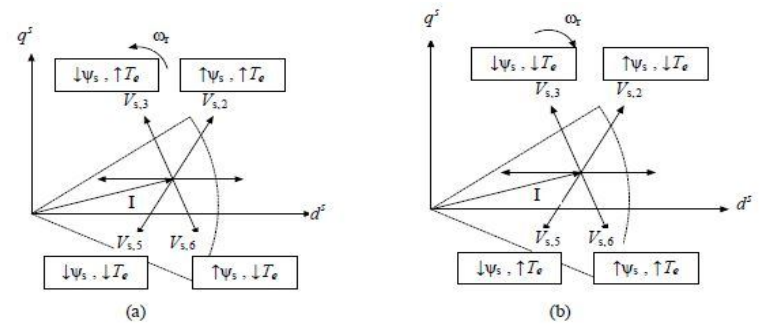

(b)

Figure 9: Optimum switching voltage vector in sector-1 for (a) anti-clockwise and (b) clockwise rotation

Table 1: Lookup table for voltage vectors.

\begin{tabular}{|c|c|c|c|c|c|c|c|}
\hline$d \psi$ & $d T_{e}$ & $S<1>$ & $S<2>$ & $S<3>$ & $S<4>$ & $S<5>$ & $S<6>$ \\
\hline \multirow{3}{*}{1} & 1 & $\mathrm{~V}_{2}(110)$ & $\mathrm{V}_{3}(010)$ & $\mathrm{V}_{4}(011)$ & $\mathrm{V}_{5}(001)$ & $\mathrm{V}_{6}(101)$ & $\mathrm{V}_{1}(100)$ \\
\cline { 2 - 8 } & 0 & $\mathrm{~V}_{0}(000)$ & $\mathrm{V}_{7}(111)$ & $\mathrm{V}_{0}(000)$ & $\mathrm{V}_{7}(111)$ & $\mathrm{V}_{0}(000)$ & $\mathrm{V}_{7}(111)$ \\
\cline { 2 - 8 } & -1 & $\mathrm{~V}_{6}(101)$ & $\mathrm{V}_{1}(100)$ & $\mathrm{V}_{2}(110)$ & $\mathrm{V}_{3}(010)$ & $\mathrm{V}_{4}(011)$ & $\mathrm{V}_{5}(001)$ \\
\hline \multirow{3}{*}{-1} & 1 & $\mathrm{~V}_{3}(010)$ & $\mathrm{V}_{4}(011)$ & $\mathrm{V}_{5}(001)$ & $\mathrm{V}_{6}(101)$ & $\mathrm{V}_{1}(100)$ & $\mathrm{V}_{2}(110)$ \\
\cline { 2 - 7 } & 0 & $\mathrm{~V}_{7}(111)$ & $\mathrm{V}_{0}(000)$ & $\mathrm{V}_{7}(111)$ & $\mathrm{V}_{0}(000)$ & $\mathrm{V}_{7}(111)$ & $\mathrm{V}_{0}(000)$ \\
\cline { 2 - 7 } & -1 & $\mathrm{~V}_{5}(001)$ & $\mathrm{V}_{6}(101)$ & $\mathrm{V}_{1}(100)$ & $\mathrm{V}_{2}(110)$ & $\mathrm{V}_{3}(010)$ & $\mathrm{V}_{4}(011)$ \\
\hline
\end{tabular}

\subsubsection{Direct Flux Control}

In stationary reference frame the stator flux equation can be written as:

$$
\overline{\Psi S}=\int\left(\bar{v}_{s}-\bar{l}_{s} R_{s}\right) d t
$$

If the stator resistance drop is neglected for simplicity, the stator flux varies along the direction of applied voltage vector and the equation will be reduced to,

$$
\Delta \overline{\Psi_{s}}=\overline{V_{s}} \Delta t
$$

Which means, by applying stator voltage vector $\bar{V}_{s}$ for a time increment $\Delta t, \overline{\Psi_{s}}$ can be changed incrementally. The command value of the stator flux vector $\overline{\Psi_{S}}$ follows a circular trajectory, the plane of stator flux is divided into six sectors as shown in Figure 10. Each sector has a different set of voltage vector to increase or decrease the stator flux. The command flux vector rotates in anticlockwise direction in a circular path and the actual stator flux vector $\overline{\Psi_{s}}$ tracks the command flux in a zigzag path but constrained to the hysteresis band [13]. In general the active forward voltage vectors $\left(V_{s, k+1}\right.$ and $\left.V_{s, k+2}\right)$ are applied to increase or decrease the stator flux respectively when the stator flux lies in sector $k$. The radial voltage vectors $\left(V_{s, k}\right.$ and $\left.V_{s, k+3}\right)$ which quickly affect the flux are generally avoided. The active reverse voltage vectors $\left(V_{s, k-1}\right.$ and $\left.V_{s, k-2}\right)$ are used to increase or decrease the stator flux in reverse direction. The stator flux vector change due to stator voltage vector is quick whereas change rotor flux is sluggish because of its large time constant $T_{r}$. That is why $\Psi_{s}$ movement is jerky and $\overline{\Psi r}$ moves uniformly at frequency $\omega_{\mathrm{e}}$ as it is more filtered. However the average speed of both remains the same in steady state condition [14]. 


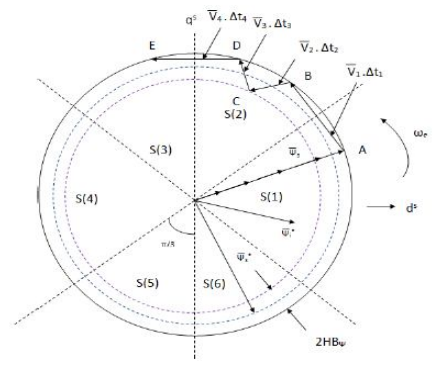

Figure 10: Circular trajectory of stator flux

\subsubsection{Stator Flux Estimation}

For exact calculation of stator flux and torque errors, an accurate estimator of stator flux is necessary. There are commonly used methods of estimation of flux namely stator voltage model and current model [8][19].

\subsubsection{Stator Voltage Model}

This is the simplest method of stator flux estimation, where the machine terminal voltages and currents are sensed and from the stationary frame equivalent circuit the fluxes are computed. The estimated stator flux is given by the following equation:

$$
\begin{aligned}
& \psi_{d s}^{s}=\int\left(v_{d s}^{s}-i_{d s}^{s} R_{s}\right) d t \\
& \psi_{q s}^{s}=\int\left(v_{q s}^{s}-i_{q s}^{s} R_{s}\right) d t \\
& \psi_{s}=\sqrt{\psi_{d s}^{s 2}}+\psi_{q s}^{s 2}
\end{aligned}
$$

This method provides accurate flux estimation at high speed but in industrial applications requiring yegtor dive dit zero start-up this method cannot be used because at low speed stator resistance drop becomes significant causing inaccurate estimation. Also at low frequency, voltage signals are very low and dc offset tends to build up at the integration output, as a result ideal integration becomes difficult [12][20].

\subsubsection{Current Model}

In stationary reference frame, current model is globally stable and the drives operation can be extended down to zero speed [8][21]. But this model is much complex as compared to voltage model as here the knowledge of rotor speed and stator current is required to estimate rotor flux linkage and stator flux can be estimated based on the estimation of rotor flux linkage. From the dynamic equations of IM in stationary reference frame, stator and rotor flux can be derived which are given below:

$$
\begin{aligned}
\frac{d}{d t} \bar{\psi} r & =\left(\left(L_{m} i_{s}-\bar{\psi} r\right) / T r\right)-\omega_{\mathrm{r}} \psi_{r} \\
\overline{\Psi_{s}} & =\frac{L_{m}}{L_{r}} \bar{\psi} r+\sigma L_{s} i_{s}
\end{aligned}
$$

Here the equations involve closed loop integration, so there is no integration drift problem in current model at low speed region. However estimation accuracy is affected due to motor parameter variation, particularly rotor resistance variation becomes dominant by skin effect and temperature. It is ideal to have a hybrid model based on the unique features gained by both models respectively where the voltage model would be effective at higher speed range and current model at lower speed range [22].

\subsubsection{Torque Hysteresis Controller}

The Torque hysteresis controller is a three level controller shown in figure 11. It means the torque control loop has three levels of digital outputs. The torque error $\Delta \mathrm{T}_{\mathrm{e}}$ is given to the torque hysteresis controller and the output is torque error status $\left(\mathrm{dT}_{\mathrm{e}}\right)$ which can have three values $-1,0$ or 1 . The width of the hysteresis band is $2 \Delta \mathrm{T}_{\mathrm{e}}$. Torque error status is given to the switching table for optimum voltage vector selection for the inverter [22].

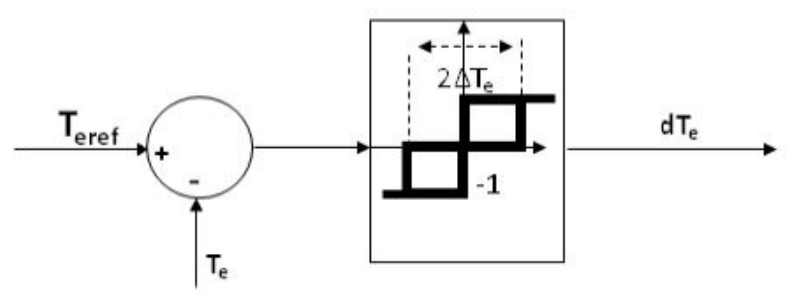

Figure 11: Torque hysteresis controller

Torque error $\Delta \mathrm{T}_{\mathrm{e}}=\mathrm{T}_{\text {eref }}-\mathrm{T}_{\mathrm{e}} \quad \ldots \ldots \ldots \ldots . .9$

$|\mathrm{dTe}|=1$ if $|\mathrm{Te}|<|\mathrm{Teref}|-|\Delta \mathrm{Te}|:$ Torque to be increased $|\mathrm{dTe}|=-1$ if $|\mathrm{Te}|>|\mathrm{Teref}|+|\Delta \mathrm{Te}|$ : Torque to be decreased $\Delta \mathrm{Te}|\leq| \mathrm{Te}|\leq| \mathrm{Teref}|+| \Delta \mathrm{Te} \mid$ : Torque to remain unchanged

\subsubsection{Flux Hysteresis Controller}

The flux hysteresis controller is a two level controller shown in figure 12. So the flux control loop has two digital outputs. The stator flux error $\Delta \psi_{\mathrm{s}}$ is given to the flux hysteresis controller and the output is flux error status $\left(\mathrm{d} \psi_{\mathrm{s}}\right)$ which can have two values 0 and 1 . The width of the hysteresis band is $2 \Delta \psi_{s}$. Flux error status is given to the switching table for optimum voltage vector selection for the inverter [23][24].

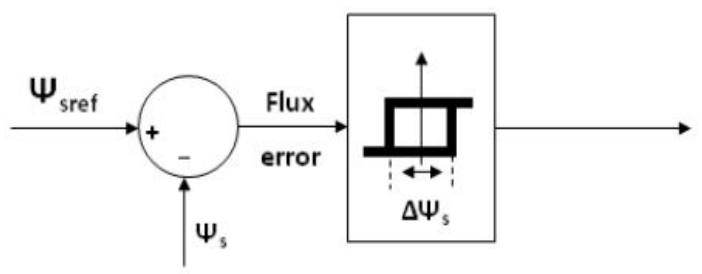

Figure 12: Flux hysteresis controller

Controller Stator flux error $\Delta \psi_{\mathrm{s}}=\psi_{\text {sref }}-\psi_{\mathrm{s}} \quad \ldots \ldots \ldots \ldots . . .10$

The flux is controlled according to the following equations: $\left|\mathrm{d} \psi_{\mathrm{s}}\right|=1$ if $\left|\psi_{\mathrm{s}}\right| \leq\left|\psi_{\text {sreet }}\right|-\left|\Delta \psi_{\mathrm{s}}\right|$ : flux to be increased. $\left|\mathrm{d} \psi_{\mathrm{s}}\right|=0$ if $\left|\psi_{\mathrm{s}}\right| \geq\left|\psi_{\text {sref }}\right|+\left|\Delta \psi_{\mathrm{s}}\right|$ : flux to be decreased. 


\section{PROPORTIONAL -INTEGRAL (PI) CONTROLLER}

In this paper complete mathematical model of induction motor is described and simulated in MATLAB-SIMULINK. The performance of FOC drive with proportional plus integral (PI) controller are presented and analyzed. One common linear control strategy is proportional-integral (PI) control. Therefore, preliminary results can be obtained within a short development period. Fuzzy control is based on fuzzy logic, which provides an efficient method to handle in exact information as basis reasoning. With fuzzy logic it is possible to convert knowledge, which is expressed in an uncertain form, to an exact algorithm. In fuzzy control, the controller can be represented with linguistic if-then rules [17]. Control law used for this strategy is given by:

$$
\mathrm{T}=\mathrm{Kp} \mathrm{e}+\mathrm{Ki} \int \mathrm{e} \mathrm{dt}
$$

Its output is the updating in PI controller gains ( $\mathrm{Kp}$ and $\mathrm{Ki})$ based on a set of rules to maintain excellent control performance even in the presence of parameter variation and drive nonlinearity. The use of PI controllers for speed control of induction machine drives is characterized by an overshoot during tracking mode and a poor load disturbance rejection. This is mainly caused by the fact that the complexity of the system does not allow the gains of the PI controller to exceed a certain low value. At starting mode the high value of the error is amplified across the PI controller provoking high variations in the command torque. If the gains of the controller exceed a certain value, the variations in the command torque become too high and will destabilize the system. To overcome this problem we propose the use of a limiter ahead of the PI controller [7]. This limiter causes the speed error to be maintained within the saturation limits provoking, when appropriately chosen, smooth variations in the command torque even when the PI controller gains are very high. The motor reaches the reference speed rapidly and without overshoot, step commands are tracked with almost zero steady state error and no overshoot, load disturbances are rapidly rejected and variations of some of the motor parameters are fairly well dealt-with [23]. In the next chapter we will discuss about the PI controller and designing of PI controller.

\section{GENETIC ALGORITHM BASED PID CONTROLLER}

Genetic algorithm (GA) uses the principles of evolution, natural selection and genetics from natural biological systems in a computer algorithm to simulate evolution. Essentially, the genetic algorithm is an optimization technique that performs a parallel, stochastic, but directed search to evolve the fittest population [23][31]. The structure of a control system with GA-PID as a controller is shown in the Figure 13 and flowchart in figure 14. It consists of a conventional PID controller with its parameter optimized by genetic algorithm. The initial population of size $\mathrm{N}$ is generated randomly to start the optimization process. The next generation can be obtained through the genetic operators. The genetic operators are the most important features of GA and are described below.

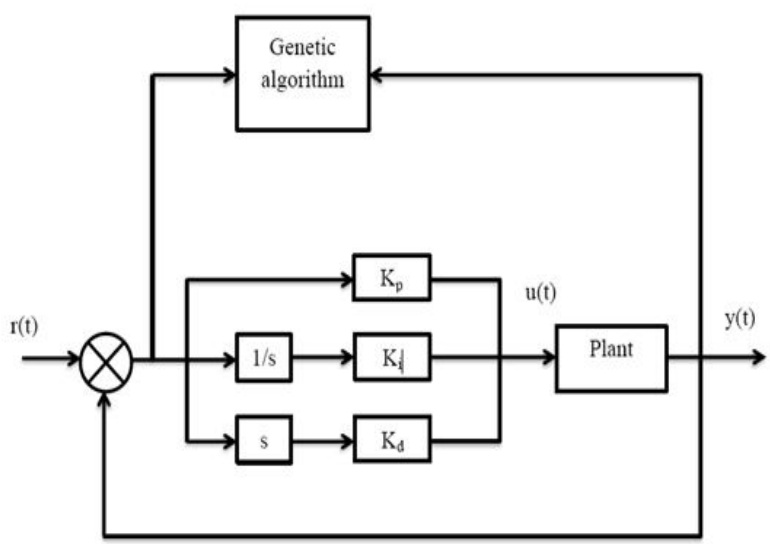

Figure 13: Structure of GA-PID controller

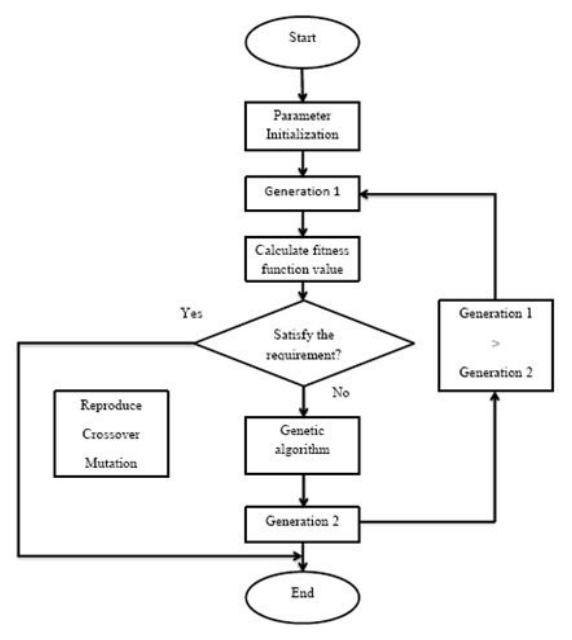

Figure 14: Flow-chart for auto tuning GA-PID controller

\section{SIMULATION MODELS}

\subsection{Mathematical Model of IM}

The three phase induction motor model is simulated by using the Matlab/Simulink Using the set of equations provided in this paper and the model is implemented [26]. Figure 15 and figure 16 depicts the complete Simulink model of IM. The performance of the motor is first checked out for no load condition and then the load torque of $1 \mathrm{Nm}$ is applied and performance characteristics are drawn.

The specifications of the IM used are:

$1.5 \mathrm{KW}, 1440 \mathrm{rpm}, 4$ pole, 3 -phase

parameters: $r_{s}=6.03 \mathrm{ohm}, \mathrm{r}_{r}=6.085 \mathrm{ohm}$

$L_{s}=L_{r}=489.3 \mathrm{mH}$

$M=450.3 \mathrm{mH}$

$\mathrm{J}=0.00488 \mathrm{Kg} \cdot \mathrm{m}^{2}$

$\mathrm{B}=0.01 \mathrm{Nm} . \mathrm{sec} / \mathrm{rad}$ 


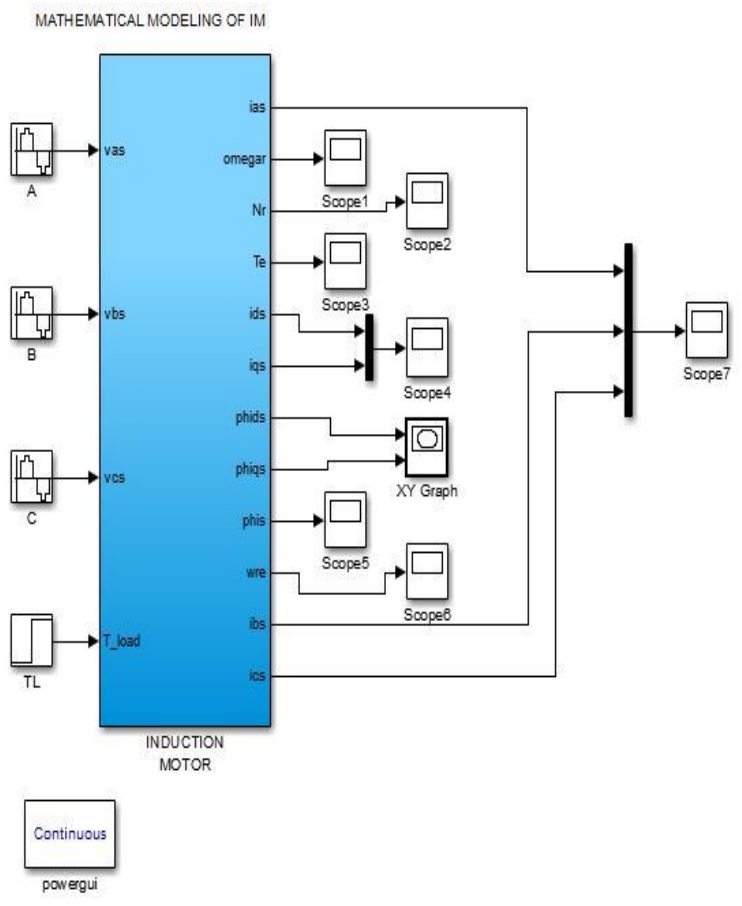

Figure 15: Complete simulation model of induction motor.

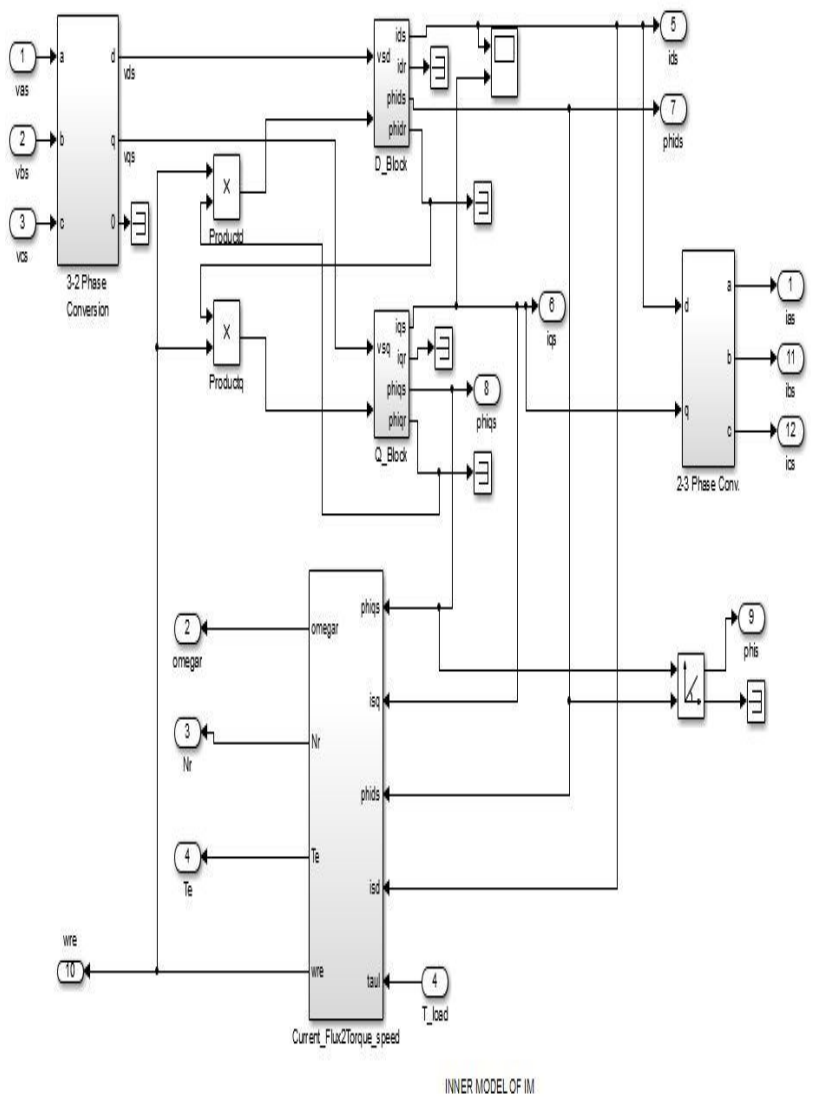

Figure 16: Inner model of Induction Motor

\section{RESULTS FOR LOAD CONDITION; $\left(T_{L}=1\right.$ N.m $)$}

Figure no. 17 (a), 17 (b), 17(c) and 17 (d) shows the modeling results of induction motor drive using MATLAB.

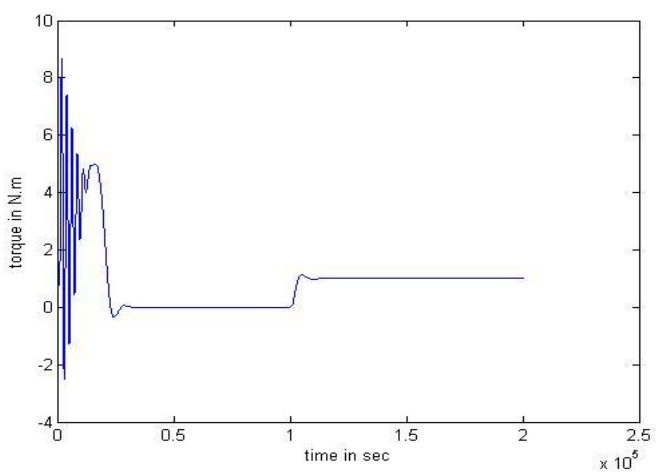

Figure 17 (a) Electromagnetic torque

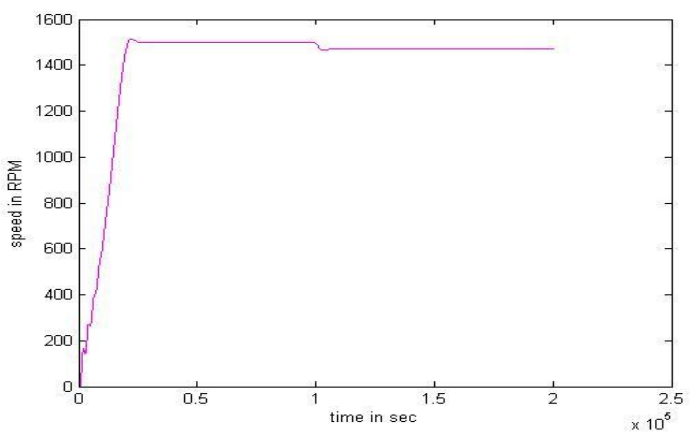

Figure 17 (b): Rotor speed

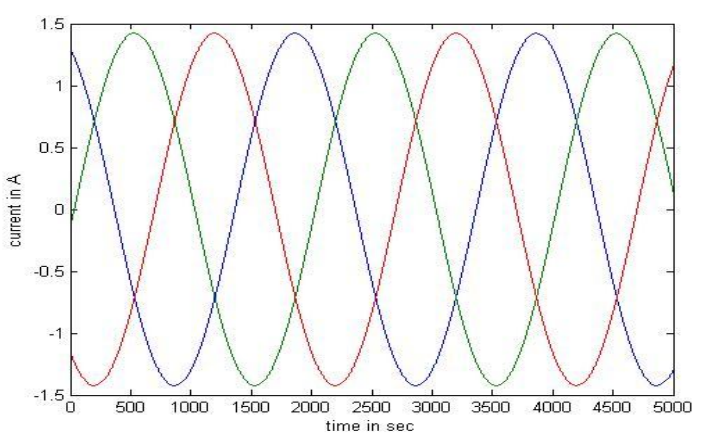

Figure 17 (c): Stator current

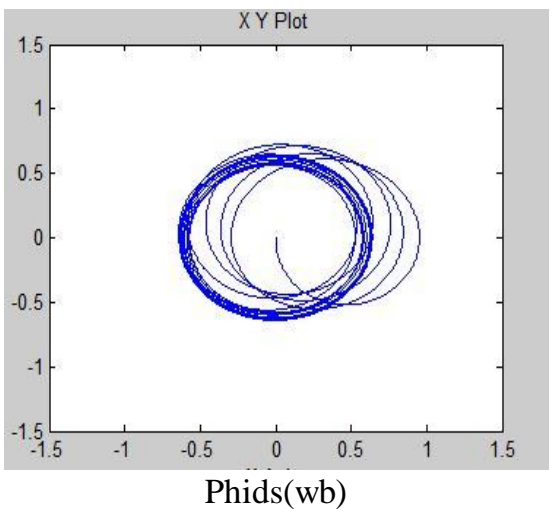

Figure 17 (d): Trajectory of d axis and q axis stator flux in stationary reference frame. 


\subsection{Simulation Model of DTC Scheme using GA}

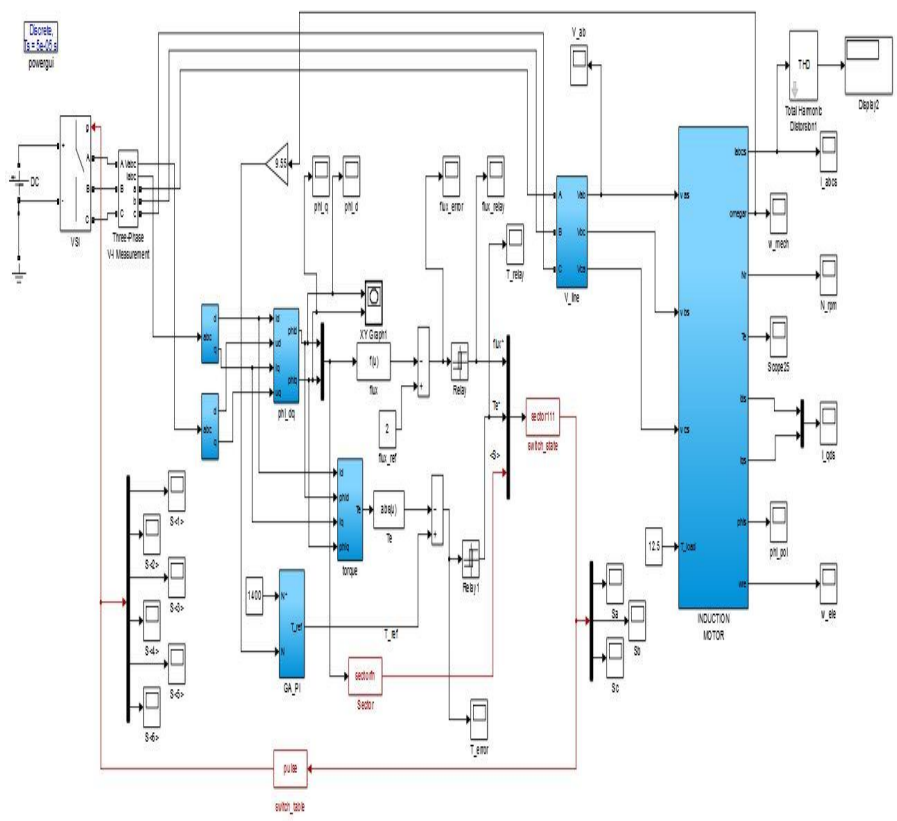

Figure 18: Simulink model of DTC scheme of IM using MATLAB programming \& GA

A direct torque control algorithm of Induction motor drive has been simulated using Matlab/Simulink. The reference flux linkage is taken as $2 \mathrm{~Wb}$ and load torque applied is $12.5 \mathrm{Nm}$. The motor is fed from an IGBT PWM VSI (Universal bridge). The MATLAB coding for stator flux sector selection, switching states for VSI, switching table \& genetic algorithm are run. The transient performance of the developed DTC model has been tested by applying a load torque command on the mechanical dynamics. The model is run for typical conditions of reference speed and applied torque value. Figure 18 depicts the complete Simulink model of DTC scheme of IM. A $50 \mathrm{HP}, 440 \mathrm{~V}, 50 \mathrm{~Hz}, 4$ pole, 3-phase induction motor is used for the simulation.

\subsection{Results comparison of DTC Scheme of IM \& DTC Scheme of IM USING GA:}

Figure 19 (a) shows the electromagnetic torque and Figure 19 (b) shows the rotor speed of the DTC based machine \& Figure 19 (c) shows the stator current of IM drive.

Figure 20 (a) shows the electromagnetic torque of the DTC based machine using Genetic Algorithm.

Figure 20 (b) shows Rotor speed of DTC scheme of IM using GA.

Figure 20 (c) shows stator current of DTC scheme of IM using GA

Figure 21 shows trajectory of $\mathrm{d}$ axis and q axis stator flux in stationary reference frame of DTC scheme of IM using GA.

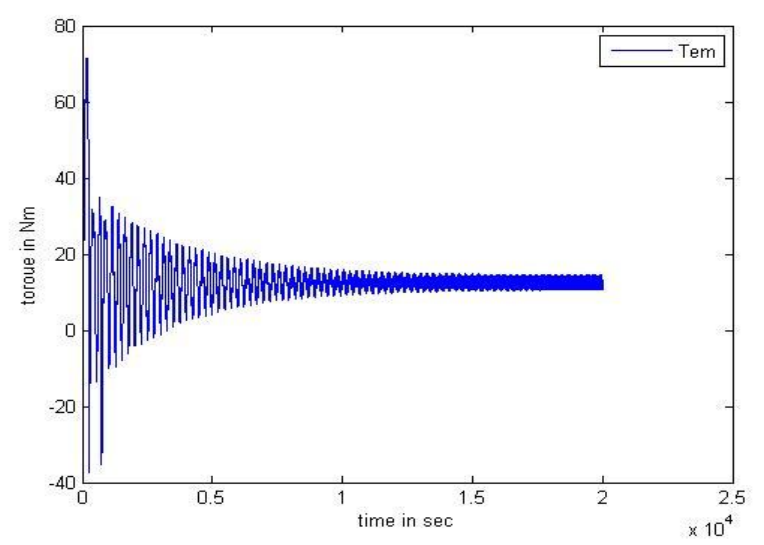

Figure 19 (a): Electromagnetic Torque of DTC scheme of IM

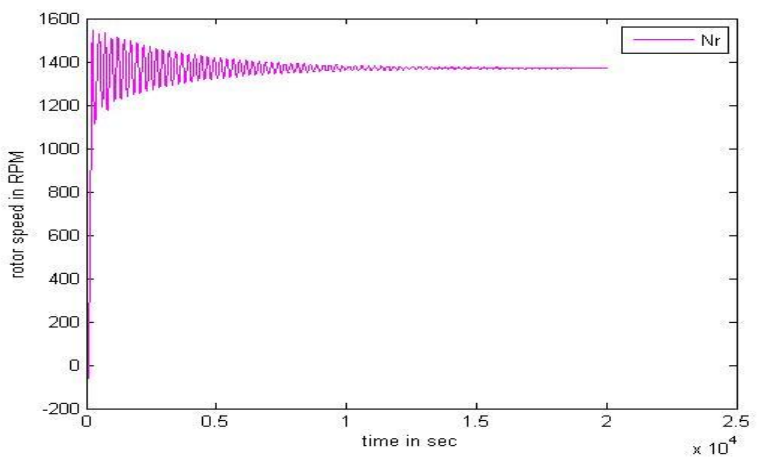

Figure 19 (b): Rotor speed of DTC scheme of IM

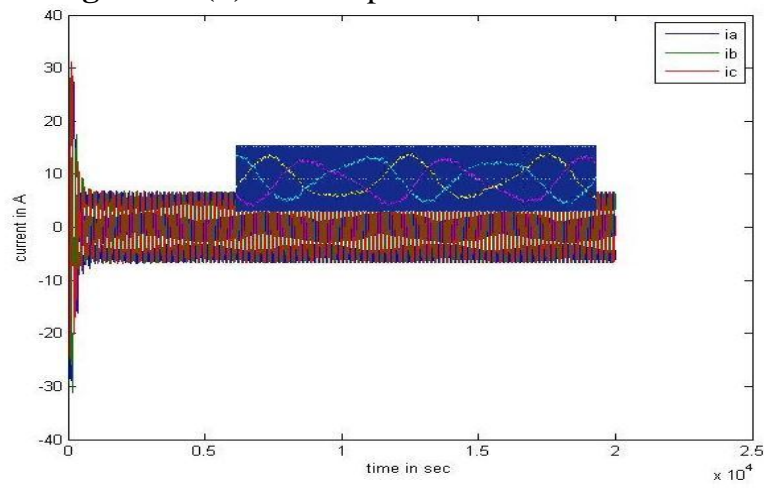

Figure 19 (c): stator current of DTC scheme of IM

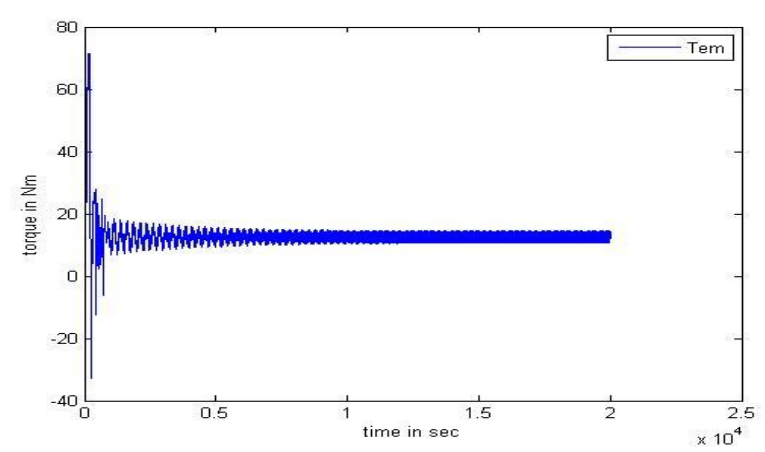

Figure 20 (a): Electromagnetic Torque of DTC scheme of IM using GA 


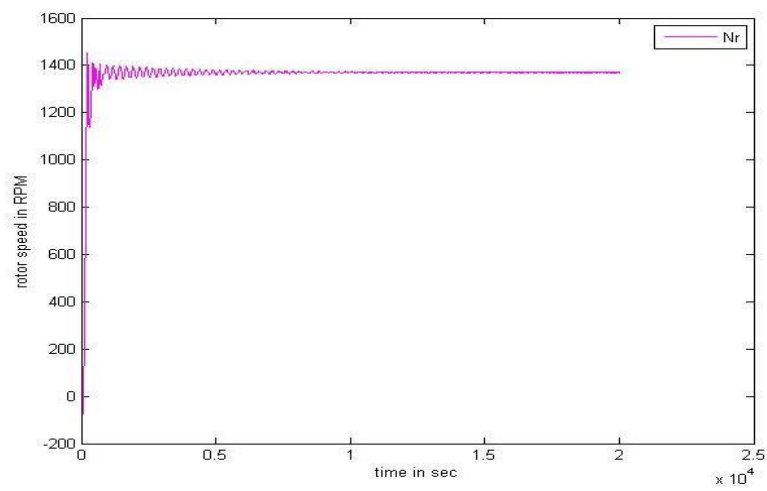

Figure 20 (b): Rotor speed of DTC scheme of IM using GA

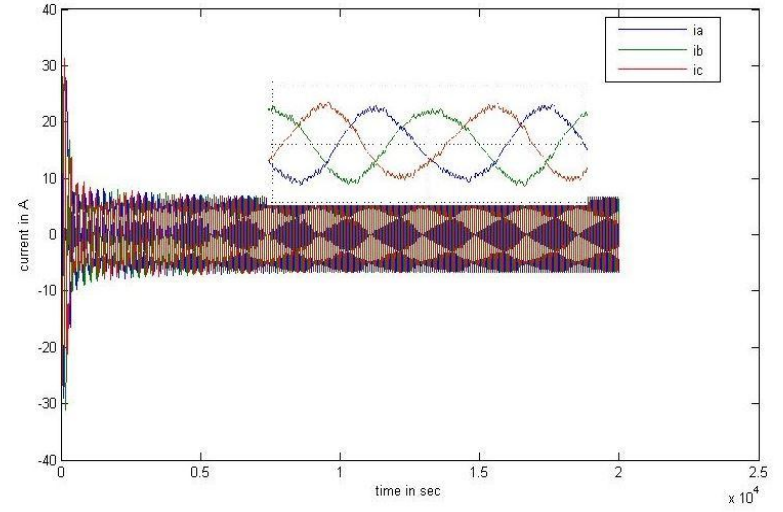

Figure 20 (c): stator current of DTC scheme of IM using GA

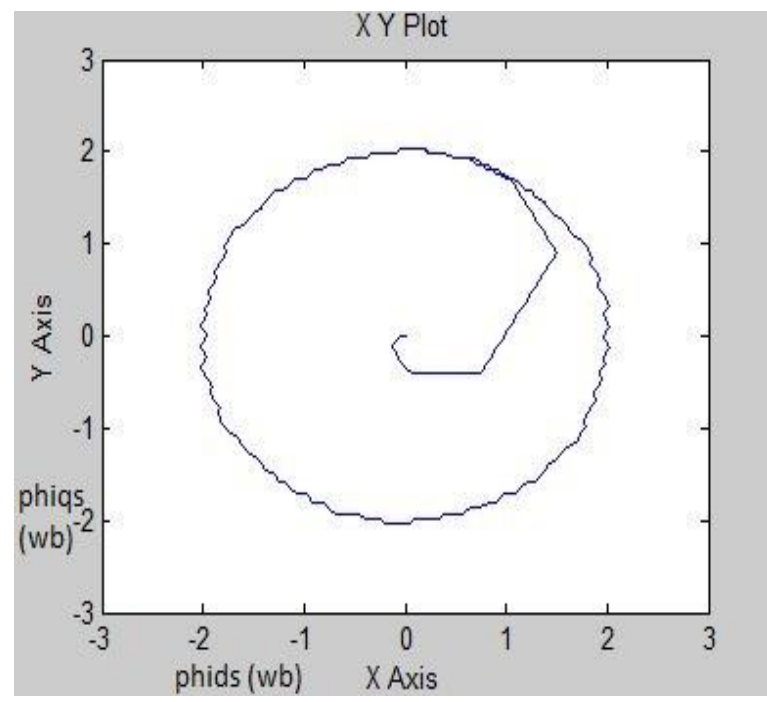

Figure.21: Trajectory of $\mathrm{d}$ axis and $\mathrm{q}$ axis stator flux in stationary reference frame of DTC scheme of IM using GA

\subsection{FFT Analysis \& THD Calculation}

The FFT analysis \& THD [25] of DTC scheme and DTC scheme using GA are shown in Figure 22 \& Figure 23 respectively.

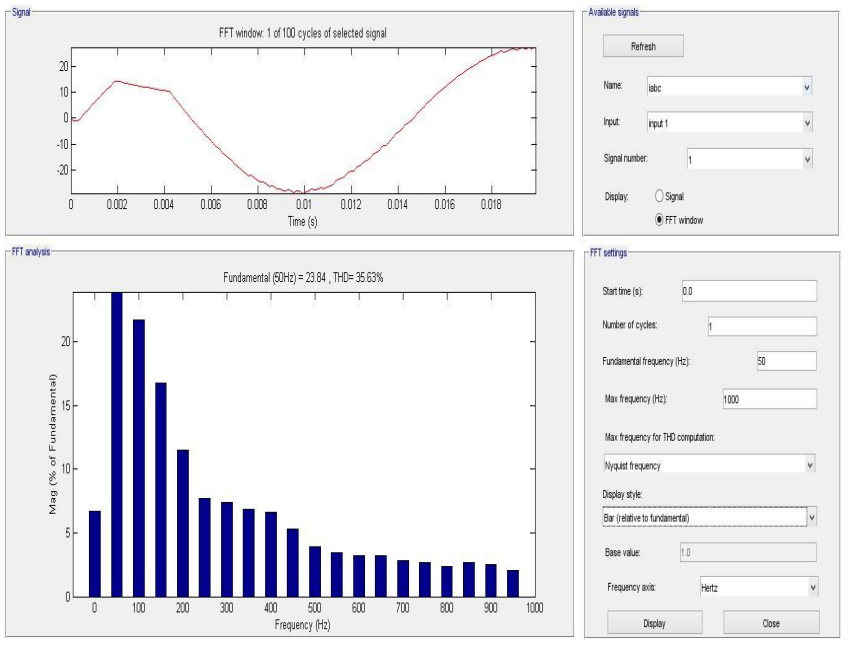

Figure.22: FFT analysis \& THD of DTC scheme

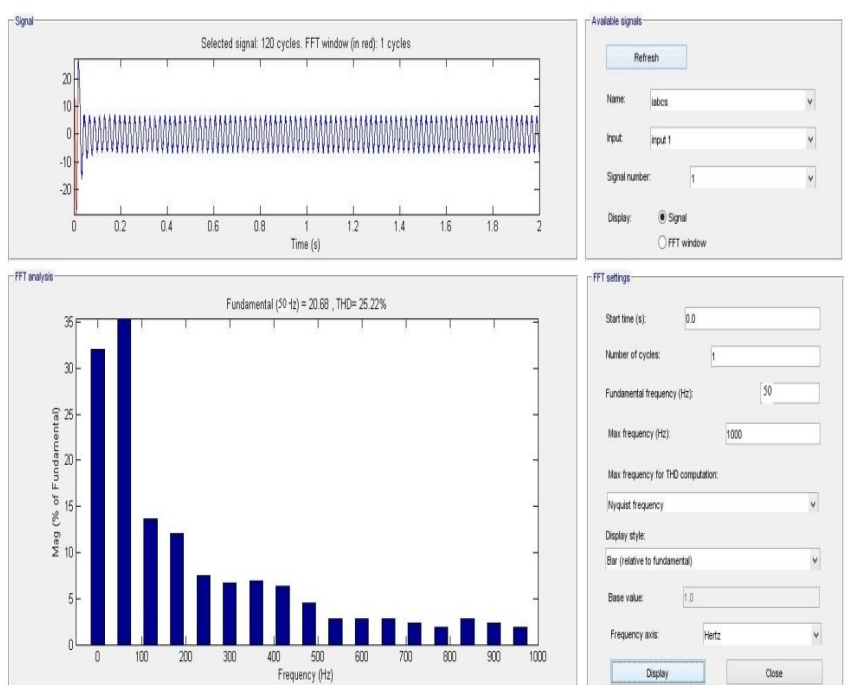

Figure 23: FFT analysis \& THD of DTC scheme using GA

\section{CONCLUSION}

The results demonstrate that the developed DTC achieved high dynamic performance in speed response to changes in demand torque. However, there is some performance degradation with torque overshoot in the torque transient owing to the hysteresis controllers used. From the results of electromagnetic torque it is seen that the torque has high initial value in the acceleration zone, increases due to load torque increment then decreases and remains constant in the deceleration zone. However the torque performance can be enhanced if we implement GA principle in the speed control loop to set the optimized values of Kp \& Ki. Figure 20 (b) and Figure 20 (c) shows how the ripple content of stator current can be reduced by using the GA. For DTC scheme the most important thing is to demonstration of switching table which can be modeled by using SIMULINK or can be developed by MATLAB coding. Appendix II, Appendix III \& Appendix IV reflects the complete MATLAB coding for DTC scheme.

DTC scheme uses stationary $d$ - $q$ reference frame with $d$-axis aligned with the stator axis. Stator voltage space vector 
defined in this reference frame control the torque and flux. The main inferences from this work are:

- In transient state, by selecting the fastest accelerating voltage vector which produces maximum slip frequency, highest torque response can be obtained.

- In steady state, the torque can be maintained constant with small switching frequency by the torque hysteresis comparator by selecting the accelerating vector and the zero voltage vectors alternately.

- In order to get the optimum efficiency in steady state and the highest dynamic response in transient state at the same time, the PI controller in the speed control loop should be tuned by the best fitness values of $\mathrm{Kp} \& \mathrm{Ki}$.

- The current, torque\& flux ripple can be minimized to some extent by employing GA technique.

The estimation accuracy of stator flux is very much essential which mostly depends on stator resistance because an error in stator flux estimation will affect the behavior of both torque and flux control loops. From the FFT analysis of stator current it is observed that the THD can be reduced by 10 percent.

\section{REFERENCES}

[1] Takahashi Isao, Noguc hi Tos hihiko, „“A New Quick-Response and High-Efficiency Control Strategy of an Induction Motor", IEEE Transactions on Industry Applications, Vol. IA-22 No-5, Sept/Oct 1986.

https://doi.org/10.1109/TIA.1986.4504799

[2] Giuseppe Buja, Domenico Casadei, and Giovanni Serra, "Direct Torque Control Of Induction Motor Drives" ,IEEE Transactions, Catalog Number: 97th8280,1997.

[3] Victor Perelmuter, "A Simplified Modeling Of Induction Motor Drives With Direct Torque Control",IEEE International conference, ISIE'99 - Bled, Slovenia, august 1999.

[4] Alfiedo Nava-Segura, Carlos Hembdez-Arhburo, Gerardo Mino, "Instantaneous Space Vector Model for Direct Flux and Torque Control of an Inverter Controlled Induction Motor" IEEE International conference,CIEP,Acapulco,Mexico,ocober 2000.

[5] B. K. Bose, Modern Power Electronics and AC Drives.Englewood Cliffs, NJ: Prentice- Hall, 2001.

[6] R. Krishnan Electric Motor Drives - Modeling, Analysis, and Control, 2001.

[7] Renato A. Krohling, Joost P. Rey, "Design of Optimal Disturbance Rejection PID Controllers Using Genetic Algorithms" IEEE Transactions On Evolutionary Computation, Vol. 5, No. 1, February 2001.

https://doi.org/10.1109/4235.910467

[8] Lixin Tang, M.F. Rahman, "A New Direct Torque Control Strategy for Flux and Torque Ripple Reduction for Induction Motors Drive-A Matlab/Simulink Model", IEEE Transaction,2001.

[9] Vanja Ambrožic, Giuseppe S. Buja ,Roberto Menis, “ Band-Constrained Technique for Direct Torque Control of Induction Motor" IEEE transactions on industrial electronics, vol. 51, no. 4, august 2004.

https://doi.org/10.1109/TIE.2004.831722

[10] Jagdish G. Chaudhari, Sandeep K. Mude, Prakash G. Gabhane, "high performance direct torque control ofinduction motor using space vector modulation" IEEE CCECE/CCGEI, Ottawa, May 2006.

[11] Manuele Bertoluzzo, Giuseppe Buja, Roberto Menis, "A direct torque control scheme for induction motor drives using the current model flux estimation" 2007 IEEE. https://doi.org/10.1109/DEMPED.2007.4393092

[12] L. Aarniovuori, L. Laurila, M. Niemelä and J. Pyrhönen "Comparison of the Induction Motor Simulation Models Analytical and FEM -in Drive System Controlled with Direct Torque Control", IEEE transaction on International Symposium on Power Electronics, Electrical Drives, Automation and Motion ,Mar 2008.

[13] Farouk M. Abdel-kader, A. EL-Saadawi, A. E. KALAS, Osama M.EL-baksawi, "Study In Direct Torque Control of Induction Motor By Using Space Vector Modulation", IEEE transaction,2008. https://doi.org/10.1109/MEPCON.2008.4562298

[14] Sifat Shah, A. Rashid, MKL Bhatti, "Direct Quadrate (D-Q) Modeling of 3-Phase Induction Motor Using MatLab / Simulink"Canadian Journal on Electrical and Electronics Engineering Vol. 3, No. 5, May 2012.

[15] M. Satheesh Kumar, P. Ramesh Babu, S. Ramprasath , "Four Quadrant Operation of Direct Torque Control-SVPWM Based Three Phase Induction Motor Drive in MATLAB/Simulink Environment" IEEE International Conference on Advanced Communication Control and Computing Technologies,2012.

[16] Angelo A. Beltran Jr., "Direct Torque Control-Based Space Vector Pulse Width Modulation Of A Two Level Inverter-Fed Three Phase Alternating Current Induction Motor Using Matlab/Simulink", Institute of Electronics Engineers of the Philippines (IECEP) Journal Vol. 1, No. 1, pp. 27 - 36, july 2012.

[17] Pradeep Ranjan Tripathy, Bibhu Prasad Panigrahi, "Simulation Studies on Switching Table based DTC and Fuzzy Rule based DTC for Three-Phase Squirrel Cage Induction Motor", ETASR - Engineering, Technology \& Applied Science Research Vol. 2, no.1, 2012.

[18] Sanila C. M., "Direct Torque Control of Induction Motor With Constant Switching Frequency" IEEE International Conference on Power Electronics, Drives and Energy Systems,Bengaluru,December 2012.

https://doi.org/10.1109/PEDES.2012.6484352

[19] Narongrit Pimkumwong, Amorn Onkrong, Tirasak Sapaklom, "Modeling and Simulation of Direct Torque Control Induction Motor Drives via Constant Volt/Hertz Technique", International Conference on Advances in 
Computational Modeling and Simulation ,Elsevier,December 2012.

https://doi.org/10.1016/j.proeng.2012.01.1166

[20] Aleck W. Leedy, "Simulink / MATLAB Dynamic Induction Motor Model for Use as a Teaching and Research Tool" International Journal of Soft Computing and Engineering (IJSCE) ISSN: 2231-2307,Volume-3, Issue-4, September, 2013.

[21] Khadim Moin Siddiqui, Kuldeep Sahay, V.K. Giri, "Performance And Analysis Of Switching Function Based Voltage Source Inverter Fed Induction Motor" International Electrical Engineering Journal (IEEJ) Vol. 5 (2014) No.9, Pp. 1545-1552, 2014.

[22] Eng.Ahmed Hassan Adel, Dr.AmrRefky, Dr.SalamaAbo-Zaid, Prof.Mahmoud Elwany,"Torque Ripple Reduction in Direct Torque Control of Induction Motor Drives by Improvement of the Switching Table", Journal of Multidisciplinary Engineering Science and Technology (JMEST), volume issue 5, December 2014.

[23] Michael J. Neath et.al., "An Optimal PID Controller For A Bidirectional Inductive Power Transfer System Using Multiobjective Genetic Algorithm", IEEE transactions on power electronics, vol. 29, no. 3, march 2014. [24] Kamal kishore chouhan, G.B.Buch, "Improved Direct Torque Control of Induction Motor", International Conference on Electrical, Electronics, Signals, Communication andOptimization(EESCO,2015. https://doi.org/10.1109/EESCO.2015.7253714

[25] Shafiq ahmedodhanoe et.al., "Maximum Efficiency Per Torque Direct Flux Vector Control Of Induction Motor Drives" IEEE Transactions On Industry Applications, Vol. 51,No.6,November/December.2015.

[26] Ibrahim Mohd Alsofyani, Nik Rumzi Nik Idris, "Simple Flux Regulation For Improving State Estimation At Very Low And Zero Speed Of A Speed Sensorless Direct Torque Control Of An Induction Motor" ,IEEE Transactions On Power Electronics, Vol. 31, No. 4, April 2016.

[27] Maria Zemzami, Norelislam Elhami, Mhamed Itmi, Nabil Hmina, "An evolutionary hybrid algorithmfor complex optimization problems", International Journal of Advanced Trends in Computer Science and Engineering, $8(2)$,

March -April2019,126-133.https://doi.org/10.30534/ijatcse/2019/0 5822019

[28] Maria Zemzami, Norelislam Elhami, Mhamed Itmi, NabilHmina, "Interoperability Optimization using a modifiedPSO algorithm", International Journal of Advanced Trends in Computer Science and Engineering, 8(2), March -April2019,101-107.https://doi.org/10.30534/ijatcse/2019/0 1822019

[29] Ganthia, B.P.; Rana, P.K.; Pattanai, S.A. "Space Vector Pulse Width Modulation Fed Direct Torque Control of Induction Motor Drive Using Matlab-Simulink”. In
Proceedings of the 3rd International Conference on Electrical, Electronics, Engineering Trends, Communication, Optimization and Sciences (EEECOS), Tadepalligudem, India, 1-2 June 2016.

[30] Ganthia B.P., Pritam A., Rout K., Singhsamant S., Nayak J. (2018) Study of AGC in Two-Area Hydro-thermal Power System. In: Garg A., Bhoi A., Sanjeevikumar P., Kamani K. (eds) Advances in Power Systems and Energy Management. Lecture Notes in Electrical Engineering, vol 436. Springer, Singapore.

[31] B. P. Ganthia, R. Pradhan, S. Das and S. Ganthia, "Analytical study of MPPT based PV system using fuzzy logic controller," 2017 International Conference on Energy, Communication, Data Analytics and Soft Computing (ICECDS), Chennai, India, 2017, pp. 3266-3269.

[32] Bibhu Prasad Ganthia, Prashanta Kumar Rana, Tapas Patra, Rosalin Pradhan, Rajashree Sahu, Design and Analysis of Gravitational Search Algorithm Based TCSC Controller in Power System, Materials Today: Proceedings, Volume 5, Issue 1, Part 1,2018, Pages 841-847, ISSN 2214-7853, https://doi.org/10.1016/j.matpr.2017.11.155.

[33] Bibhu Prasad Ganthia, Aditi Abhisikta, Deepanwita Pradhan, Anwes Pradhan, A Variable Structured TCSC Controller for Power System Stability Enhancement, Materials Today: Proceedings, Volume 5, Issue 1, Part 1, 2018, Pages 665-672, ISSN 2214-7853, https://doi.org/10.1016/j.matpr.2017.11.131.

[34] B. P. Ganthia, S. Mohanty, P. K. Rana, P. K. Sahu, "Compensation of voltage sag using dvr with pi controller", Electrical Electronics and Optimization Techniques (ICEEOT) International Conference, pp. 2138-2142, 2016.

[35] Ganthia Bibhu Prasad and Rout Krishna 2016 DEREGULATED POWER SYSTEM BASED STUDY OF AGC USING PID AND FUZZY LOGIC CONTROLLER Int. J. of Adv. Res. 4 847-855 www.journalijar.co https://doi.org/10.21474/IJAR01/823 